\title{
NIETZSCHE, PLATÓN Y DARWIN: VIDA, CREACIÓN Y NIHILISMO
}

\author{
Alonso Zengotita ${ }^{1}$ \\ Universidad de Buenos Aires (UBA) \\ (D) https://orcid.org/0000-0002-9636-6503 \\ E-mail: alonsozengotita@gmail.com
}

\section{RESUMEN:}

En el presente artículo se abordarán las relaciones entre Nietzsche y Platón, y Nietzsche y Darwin, a partir de las respectivas autocalificaciones nietzscheanas - a saber, su propia filosofía como 'platonismo invertido', y su postura 'anti-Darwin'. A partir de esto, se buscará alcanzar tres objetivos: en primer lugar, establecer que la calificación nietzscheana de 'Anti-Darwin' no se sustenta ni en una oposición de tipo ontobiológico, ni en oposición a un carácter teleológico de algún tipo, sino, principalmente, en una ruptura axiológica; en segundo lugar, mostrar la conexión entre la perspectiva nietzscheana y el platonismo, en divergencia con las perspectivas que, o ponen a Nietzsche en completa oposición al platonismo, o encuentran concordancia no con el platonismo, sino con Platón, o hallan plena continuidad entre uno y otro -el 'Nietzsche metafísico' heideggeriano. Finalmente, el tercer objetivo consistirá en mostrar que ambas autocalificaciones se hallan estructuralmente asociadas, es decir, que una no es completamente comprensible sin la otra.

PALABRAS CLAVE: Axiologia; Metafisica; Teleologia; Tactica; Gesto.

\section{NIETZSCHE, PLATO AND DARWIN: LIFE, CREATION AND NIHILISM}

\begin{abstract}
:
At the present paper, the relations between Nietzsche and Plato, and Nietzsche and Darwin, will be addressed from the respective Nietzschean self-descriptions -namely, his own philosophy as 'inverted Platonism', and his 'antiDarwin' posture. Starting from this, three objectives will be seeked for: in the first place, to establish that the Nietzschean description of 'anti-Darwin' is sustained nor on a ontobiological opposition, nor in opposition to a teleological character of any kind, but mainly in an axiological rupture; in second place, to show the connection between the Nietzschean perspective and Platonism in divergence with perspectives that either put Nietzsche in complete opposition with Platonism, or find agreement not with Platonism but with Plato, or find full continuity between each other -the Heiddegerian 'metaphysical Nietzsche'. Finally, the third objective will consist on showing that both self-descriptions are structurally associated, meaning, that one isn't completely comprehensible without the other.
\end{abstract}

KEY WORDS: Axiology; Metaphysics; Teleology; Tactics; Gesture.

\footnotetext{
${ }^{1}$ Doctor en Filosofía. Profesor en la Universidad de Buenos Aires (UBA), Buenos Aires - Argentina.
} v.20, n.2, p.244-257, junho, 2020. 


\section{Introducción}

Las perspectivas nietzscheanas respecto tanto al platonismo como al darwinismo han sido objeto de numerosos y diversos análisis. Sin embargo, dichos análisis hallan -para ambas perspectivas- un punto de anclaje común: las autocalificaciones nietzscheanas. En efecto, el modo en que Nietzsche explícitamente caracteriza su posicionamiento tanto respecto al platonismo como al darwinismo resultan un punto de tránsito y un eje obligatorios al momento de desarrollar los mencionados análisis.

Así, desde la caracterización nietzscheana de que su filosofía es "platonismo invertido" (NIETZSCHE, 2008, 7[156]) se produce, como señala Vermal (2010), el punto de partida del canónico análisis heideggeriano, que pone a Nietzsche como el último de los metafísicos ${ }^{2}$. En otro tipo de análisis, dicho platonismo invertido se ha leído, como en el caso de Brobjer (2004), Sena (2004), Lampert (2004) o Müller (2010), desde una separación entre el platonismo y la figura de Platón, rescatada por Nietzsche; en otros, esa inversión es tomada solamente para ser luego deslegitimada como tal: así -sólo por mencionar algunos ejemplos- Sánchez Taborda (2012) piensa a Nietzsche como oposición antimetafísica a Platón, como asimismo lo hace Wiehl (1990) en su Nietzsches Antiplatonismus; aquí, lo inverso se halla pensado directamente como lo opuesto. En estas perspectivas, entonces, -exceptuando el caso heideggeriano- no se muestra un punto de concordancia con el platonismo -en aquellos que lo piensan como opuesto- o se halla más bien un punto de concordancia de Nietzsche, no con el platonismo, sino con Platón.

En el caso darwiniano, la caracterización nietzscheana es aquella de "anti-Darwin" (NIETZSCHE, 2007b, p. 95). Esta caracterización de contraposición es tomada, en numerosas lecturas, desde una perspectiva onto-biológica de lo vital en Nietzsche. Es el caso de Norris (1990, p. 1235), quien, frente a las categorías vitales de Darwin, piensa a la voluntad de poder nietzscheana como "una voluntad fisiológica de crecimiento"; por su parte, Richardson (2002, p. 539) concibe de modo metafísico a la voluntad de poder (una 'power ontology'), caracterizándola "como una fuerza universal más básica que la selección darwiniana"; Mansilla (2007) retorna al registro biológico, al concebir que Nietzsche interpreta todo desarrollo civilizatorio a partir de la satisfacción, directa o indirecta, de impulsos -eliminando toda complejidad del entramado social; en esta línea, Seigfried (1990) concibe la afirmación nietzscheana como una ontología de empoderamiento tecnocientífico -perspectiva en la que encolumna a la crítica heideggeriana. Desde una perspectiva opuesta a la ontobiológica, tanto Cano (2015) como Bacarlett Pérez (2006) ponen a la vida en Nietzsche como principio antiteleológico la primera, y como conjunto de fuerzas en constante conflicto la segunda. Ambas, entonces, disponen a Nietzsche enfrentado con un principio vital traducible en una teleología -carácter, este último, propio del campo darwiniano.

En el presente artículo buscaremos alcanzar tres objetivos: establecer que la calificación nietzscheana de 'Anti-Darwin' no se sustenta ni en una oposición de tipo ontobiológico, ni en oposición a un carácter teleológico de algún tipo sino, principalmente, en una ruptura axiológica; mostrar la conexión entre la perspectiva nietzscheana y el platonismo, en divergencia con aquella perspectiva que presentan Heidegger y los otros autores mencionados; y finalmente, mostrar que ambas autocalificaciones se hallan estructuralmente asociadas, es decir, que una no es completamente comprensible sin la otra.

\footnotetext{
${ }^{2}$ Según Vermal, '[1]a lectura de Heidegger no es una interpretación usual que intentaría presentar 'lo que Nietzsche realmente dijo', sino que lo interpreta desde un proyecto [...]' (VERMAL, 2000, p. 98), proyecto que lo pone a él, Heidegger, como el primer posmetafísico.
} 
En orden de alcanzar los objetivos planteados, abordaremos primeramente un fragmento de Más allá del bien y del mal, que nos permitirá estipular tanto el lugar desde el cual resulta válido considerar la caracterización nietzscheana de 'Anti-Darwin' como también la conexión que la misma presenta respecto al platonismo.

\section{Anti-Darwin: la vida, la mirada y la táctica}

¿Cuál es el sentido en que Nietzsche sostiene una postura anti-Darwin? En orden de dilucidarlo, resulta fundamental analizar el siguiente fragmento de Jenseits von Gut und Böse:

Los fisiólogos deberían reflexionar antes de poner el impulso de conservación como impulso cardinal de los seres vivos orgánicos: ante todo, algo viviente quiere dejar salir su fuerza: la ‘conservación’ sólo es una de las consecuencias de ello. ¡Cuidado con principios teleológicos superfluos! Y entre ellos está el entero concepto de 'impulso de conservación'. (NIETZSCHE, 2007a, p. 24).

El abordaje crítico al impulso de conservación, ¿se da debido a su carácter de principio teleológico, o de principio teleológico superfluo? Es decir, ¿es el concepto de teleología como tal el que es criticado? De acuerdo al fragmento, el impulso de conservación es parte del conjunto de los principios teleológicos superfluos en tanto no es sino una consecuencia -en tanto el impulso cardinal es el de dejar salir la fuerza del viviente. Que sea por su superfluidad y no por su carácter teleológico que Nietzsche critica el impulso de conservación -como base de la struggle for existence de Darwin- se hace más evidente más evidente en el fragmento que le sigue:

En esta victoria sobre el mundo y en esta interpretación del mundo a la manera de Platón había una especie de goce distinto al que nos ofrecen los fisiólogos de hoy, y asimismo los darwinistas y antiteleólogos entre los trabajadores de la fisiología, con su principio de la 'fuerza mínima' y la estupidez máxima. 'Allí donde el hombre no tiene ya nada que ver y agarrar, tampoco tiene nada que buscar', éste es, desde luego, un imperativo distinto del platónico [...] acaso sea el apropiado para una estirpe ruda y trabajadora [...] los cuales no tienen que realizar más que trabajos groseros. (NIETZSCHE, 2007a, p. 25).

Los antiteleólogos y los darwinistas son considerados como 'trabajadores de la fisiología' en tanto ambos parten del principio sensualista -sólo existe lo experimentable por los sentidos y por ello, Darwin y Spencer no pueden ver la enorme capacidad que implican las fuerzas internas del ser vivo. Al ser los impulsos cardinales inaccesibles para el sensualista, es que la postura darwinista es equiparada a la del antiteleólogo en el tamaño de su estupidez - de su ceguera.

Ante la perspectiva darwinista-spenceriana de un medio determinante, Nietzsche establece en El crepúsculo de los ídolos:

Anti-Darwin.-En lo que se refiere a la famosa 'lucha por la vida', a mí a veces me parece más aseverada que probada. Se da, pero como excepción; el aspecto de conjunto de la vida no es la situación calamitosa, la situación de hambre, sino más bien la riqueza, la exuberancia, incluso la prodigalidad absurda, -donde se lucha, se lucha por el poder... No se debe confundir a Malthus con la naturaleza.

Si es la frugalidad del medio la que determina al viviente a la adaptación, Nietzsche deshace la razón de ser de la 'lucha por la existencia' al hacer a la vida pródiga. Malthus, 
economista británico, establece en An Essay on the principle of population (1789) que mientras la población humana crece geométricamente, los medios de subsistencia lo hacen de modo aritmético -y por ende, hace al medio algo comparativamente pobre. Nietzsche denuncia, al hablar de Malthus, una transferencia de la evolución económica humana al carácter mismo de la naturaleza -es decir, una caracterización tendenciosa de la misma.

Pero suponiendo que esa lucha exista -y de hecho se da-, termina, por desgracia, al revés de cómo lo desea la escuela de Darwin, al revés de como acaso sería lícito desearlo de ella: a saber, en detrimento de los fuertes, de los privilegiados, de las excepciones afortunadas. (NIETZSCHE, 2007b, p. 95)

No se trata entonces de que la vida sea solamente prodigalidad -como Nietzsche afirma, la struggle for existence existe- sino que el pensarla en términos de pura estrechez lo que produce es el recorte de potencialidades vitales. La problemática darwinista no pasa por el formato teleológico con que pueda pensarse la vida, sino por el empequeñecimiento vital que implica la específica teleología darwinista-spenceriana. De hecho, el darwinismo no implica en sí teleología. La selección natural, señala Pichot, se sustenta en cuatro principios: no alcanzan los recursos naturales para alimentar a la población, lo cual hace que se luche por obtenerlos; los miembros hacia dentro de una misma especie presentan variabilidad de caracteres; aquellos cuyos caracteres resultan ventajosos resultan favorecidos para obtener los recursos; esas diferencias favorables crean a través de la herencia especies nuevas ${ }^{3}$. Como marca Cano (2015, p. 58), si alguno de estos principios desapareciera no se produciría la selección natural -al menos, como la concibe Darwin- con lo cual que no existe una teleología darwinista per $s^{4}$. ¿Por qué Nietzsche lo piensa en términos teleológicos?

Todo el mundo conoce el libro del célebre Cornaro, en que el autor recomienda la rigurosa dieta que él observaba para conseguir una vida larga y feliz al mismo tiempo que virtuosa. [...] Estoy convencido de que ningún libro (exceptuando la Biblia, por supuesto) ha hecho tanto daño ni ha abreviado tantas existencias como este singular engendro, escrito con buena intención, sin duda. El motivo es una confusión entre el efecto y la causa. Aquel buen italiano creía que su dieta era la causa de su longevidad, cuando lo que sucedía es que la condición primera para vivir mucho, la lentitud extraordinaria en la asimilación y desasimilación y el escaso consumo de sustancias nutritivas eran, en realidad, la causa de su dieta. (NIETZSCHE, 2007b, p. 46)

Desde la lectura nietzscheana no es la dieta lo que hace al cuerpo de Cornaro -sino el cuerpo a la dieta; asimismo, en la selección natural lo que existe no es, justamente, algo 'natural', sino un tipo vital ya presupuesto. En términos de construcción conceptual se trata entonces de una teleología: la adaptabilidad de la vida, presupuesta, lleva a fabricar un edificio discursivo que justifique la 'naturalidad' de la misma. Así, el uso de la lectura malthusiana de la economía humana da cuenta del doble movimiento que conforma la estructura teleológica leída por Nietzsche en el darwinismo: por un lado, caracteriza al medio de modo de producir como efecto la lucha por la existencia; por otro, usar encubiertamente a Malthus para caracterizar al medio da cuenta del deslizamiento de valoraciones propias de lo humano para pensar lo natural. Es entonces a partir de una determinada valoración de la vida que se despliega la dinámica de la selección natural -y así, la misma presenta carácter teleológico. Desde aquí, como valoración,

${ }^{3}$ Cfr. PICHOT, 1993, p. 790 y ss.

${ }^{4}$ Al respecto, Fornari sostiene incluso que Nietzsche era conciente de la vocación antiteleológica darwinista (2002, p. 100).

ZENGOTITA, Alonso. Nietzsche, Platón y Darwin: vida, creación y nihilismo. Griot : Revista de Filosofia, Amargosa - BA, v.20, n.2, p.244-257, junho, 2020. 
como tipología que busca ser impuesta, el aumento vital nietzscheano en términos de un plus de poder puede ser asimismo caracterizado como teleológico. Volviendo a la sentencia nietzscheana:

Pero suponiendo que esa lucha exista -y de hecho se da-, termina, por desgracia, al revés de cómo lo desea la escuela de Darwin, al revés de como acaso sería lícito desearlo de ella: a saber, en detrimento de los fuertes, de los privilegiados, de las excepciones afortunadas. (NIETZSCHE, 2007b, p. 95)

Se trata de lo que sería lícito desear de la escuela darwiniana -v. gr., lo que se busca favorecer desde la perspectiva nietzscheana: el aumento, de los privilegiados, de los fuertes, de las excepciones afortunadas. Ahora bien, ¿no muestra el darwinismo el triunfo de los mejor capacitados, de aquellos con más recursos? Sí, pero a partir de otra concepción de 'mejor': son los que mejor se adaptan al medio, sobreviven y se multiplican -los que tienen éxito en la lucha por la existencia. Ese éxito es el fracaso desde la perspectiva de una vida que tiende al plus de poder. Desde la lectura nietzscheana, que invierte los términos -que considera al discurso según sus efectos, como en el ejemplo de Cornaro- cobra pleno sentido pensar al viviente darwiniano como propio de una teleología superflua, y al nietzscheano desplegando una teleología del central impulso del viviente. Esa perspectiva teleológica hace explícito que es el discurso (científico o no) el que sirve a un tipo vital, y no a la inversa.

La pregunta nietzscheana por el hombre a querer ${ }^{5}$ conduce a confrontar con el tipo de la vida descendente, producto del cristianismo y las 'sombras de Dios' -siendo una de las fundamentales el discurso darwinista. La línea anti-antiteleológica de Nietzsche despliega así su profundidad táctica: al movilizar la posición de Darwin al plano teleológico, permite evaluarla valorativamente - tanto la de Darwin como la suya propia- a partir de sus efectos.

Los antiteleólogos y los darwinistas sólo han de realizar 'trabajos groseros', dice Nietzsche, en función de que sólo saben manejarse por el principio sensualista: lo único válido es lo captable vía sentidos, lo inmediato - postura muy lejana a la platónica. La cortedad de visión, desde Nietzsche, es directamente proporcional al grado de estupidez. Los darwinistas y los antiteleólogos no pueden sino interpretar desde los valores cristianos - al ser sensualistas, no pueden ver más allá- y por ende no verán sino lo que dichos valores les presentan como natural. La mirada platónica es concebida aquí como una aristocracia de la visión: el recurso teleológico aparece para desplegar lo que no se da a simple vista - no se da a los 'trabajadores de la fisiología' (physiologischen Arbeitern). Sólo quien posee una visión que trascienda lo inmediato puede separarse de la perspectiva cristiana y cambiarla por otra: el trayecto vital no está necesariamente sometido a valores permanentes impuestos desde una afuera de la vida; la vida misma puede darse otras formas, otras ficciones -otras axiologías.

Esta valoración positiva, aristocrática, ¿cómo se articula con la concepción nietzscheana del platonismo?

\section{Platón: el gesto creador y lo creado}

La crítica al platonismo resulta central en la obra nietzscheana y ha sido, como se marcó, profusamente trabajada, con lo cual se realizará una breve mención introductoria. Como establece Nietzsche en el prólogo a Más allá del bien y del mal, el platonismo es una de las 'figuras grotescas' que conforman la filosofía dogmática, pero no una más: 'el peor, el más

\footnotetext{
5 “No es mi problema qué reemplazará al ser humano: sino qué tipo de humano se debe elegir, se debe querer, se debe criar como tipo más valioso..." (NIETZSCHE, 2008, 11[413], p. 490).
} 
duradero y peligroso de todos los errores ha sido hasta ahora un error de dogmáticos, a saber, la invención por Platón del espíritu puro y del bien en sí.' (2007a, p. 22). La crítica nietzscheana a los conceptos, valores y verdades en sí encuentra entonces al platonismo -y su sucedáneo, el cristianismo $^{6}$ - como objetivo princeps; de allí deriva toda una línea de lectura que -como se mencionó en la introducción- piensa a Nietzsche en oposición completa a la concepción platónica. Sin embargo, también en el mismo prólogo, Nietzsche se pregunta: ¿¿De dónde procede esa enfermedad que aparece en la más bella planta de la Antigüedad, en Platón?' (2007a, p. 22).

Esa enfermedad que pone a lo racional en primer plano es transmitida por Sócrates; en efecto, '[h]ay en la moral de Platón algo que en propiedad no pertenece a Platón, sino que simplemente se encuentra en su filosofía, a pesar de Platón, podríamos decir, a saber: el socratismo, para el cual Platón era en realidad demasiado aristocrático.' (NIETZSCHE, 2007a, p. 190). Desde esta perspectiva surge toda otra línea de lecturas, mencionadas asimismo en la introducción, que recusan desde Nietzsche al platonismo pero rescatan a la figura misma de Platón. Ahora bien, ¿en qué sentido es aristocrático Platón? Y antes que eso, ¿qué implica 'aristocrático' para Nietzsche? En el propio Más allá del bien y del mal encontramos que '[e]sta tendencia aristocrática es, justamente, la que propende a la 'elevación (Erhöhung) del tipo hombre' (2007a, p. 197). Esto retrotrae a la primera pregunta: si lo aristocrático tiende a la elevación vital, ¿̨ómo es posible que el creador de un dogmatismo grotesco reciba ese apelativo? En orden de responder esto, habremos de retrotraernos asimismo al fragmento citado en relación a Darwin:

En esta victoria sobre el mundo y en esta interpretación del mundo a la manera de Platón había una especie de goce distinto al que nos ofrecen los fisiólogos de hoy, y asimismo los darwinistas y antiteleólogos entre los trabajadores de la fisiología, con su principio de la 'fuerza mínima' y la estupidez máxima. 'Allí donde el hombre no tiene ya nada que ver y agarrar, tampoco tiene nada que buscar', éste es, desde luego, un imperativo distinto del platónico [...] acaso sea el apropiado para una estirpe ruda y trabajadora [...] los cuales no tienen que realizar más que trabajos groseros. (NIETZSCHE, 2007a, p. 28)

¿Y cuál es esa 'victoria sobre el mundo'?

[...] justo en su oposición a la evidencia de los sentidos residía el encanto del modo platónico de pensar, que era un modo aristocrático de pensar, - acaso entre hombres que disfrutaban incluso de sentidos más fuertes y más exigentes que los que poseen nuestros contemporáneos, pero que sabían encontrar un triunfo más alto en permanecer dueños de esos sentidos: y esto, por medio de pálidas, frías, grises redes conceptuales que ellos lanzaban sobre el multicolor torbellino de los sentidos - la plebe de los sentidos, como decía Platón. (NIETZSCHE, 2007a, p. 28)

La victoria implica, aquí, el dominio de los sentidos a partir del despliegue de esas redes conceptuales -es decir, de la creación de las Ideas, que presentan una mayor entidad ontológica que aquello sentido. Aquí parecen chocar, contradiciéndose, dos visiones sobre las Ideas: son por un lado aquello que hace 'grotesco' al platonismo; por otro, aquello que pone como aristocrático el propio modo de pensar platónico. Ahora bien, esta aparente contradicción aparece asimismo en el caso del asceta: ' [...] este sacerdote ascético, este presunto enemigo de la vida, este negador, -precisamente él pertenece a las grandes potencias conservadoras y creadoras de síes de la vida...'

${ }^{6}$ El cristianismo es "platonismo para el «pueblo»." (NIETZSCHE, 2007b, p. 22).

ZENGOTITA, Alonso. Nietzsche, Platón y Darwin: vida, creación y nihilismo. Griot : Revista de Filosofia, Amargosa - BA, v.20, n.2, p.244-257, junho, 2020. 
(NIETZSCHE, 2000, p. 32). El asceta, a través de prácticas que no necesariamente coinciden con la elaboración conceptual ${ }^{7}$, propende al mismo fin: el control y el rebajamiento de los sentidos -la negación de su valor. Sin embargo, la negación del valor de los sentidos se despliega también a partir de la creación de elementos que trascienden a los mismos, y que tienen un mayor valor: un 'más allá' de los sentidos. Es desde este carácter creativo que Nietzsche califica al pensamiento platónico como aristocrático:

Los auténticos filósofos son hombres que dan órdenes y legislan: dicen "¡así debe ser!", son ellos los que determinan el "hacia dónde" y el "para qué" del ser humano, $[\ldots]$ ellos extienden su mano creadora hacia el futuro, y todo lo que es y ha sido conviértese para ellos en medio, en instrumento, en martillo. Su «conocer» es crear, su crear es legislar, su voluntad de verdad es - voluntad de poder. (2007a, p. 128)

Platón creó el mundo de las Ideas, y con ello, una dinámica de domeñamiento de los sentidos; ese gesto de la mano, que conforma, crea, es un gesto aristocrático. Las prácticas ascéticas se proyectan en el mismo sentido: crean nuevas formas, al domeñar al cuerpo y sus sensaciones. Ahora bien -retornando a la pregunta original, pero invertida- ¿por qué este pensamiento aristocrático es considerado asimismo como 'grotesco'? De hecho, ¿cómo un pensamiento aristocrático puede ser grotesco?

La creencia en el mundo que debería ser, es, existe realmente, es una creencia de improductivos que no quieren crear un mundo tal como debe ser. Lo ponen como existente, buscan los medios y caminos para llegar a él. 'Voluntad de verdad' como impotencia de la voluntad de crear. (NIETZSCHE, 2008, 9[60], p. 250).

El platonismo, por un lado, implica un gesto aristocrático: crea el mundo de las Ideas, genera una práctica de domeñamiento de los sentidos; por otro lado, pone a esas Ideas como perfectas y eternas. En tanto perfectas, deshacen la necesidad de posterior creación alguna; en tanto eternas, las caracterizan como siempre existentes -es decir, increadas; implican el borramiento del propio gesto creador. Según Nietzsche, Platón tiene una visión aristocrática, enferma a partir de la influencia socrática. El gesto propio del pensamiento platónico es aristocrático -implica, en las palabras de Nietzsche, una voluntad de verdad que es voluntad de poder. El carácter propio de aquello creado, las Ideas, está influenciado por la enfermedad socrática: voluntad de verdad como impotencia de la voluntad de crear -la verdad existe, es eterna y perfecta, y por ende no hay porqué crear nada. Respondiendo a la pregunta: el pensamiento aristocrático no es grotesco -lo es su producto enfermo ${ }^{8}$.

De esta manera, el 'platonismo invertido' de Nietzsche cobra otro sentido: no es una completa oposición al platonismo, ni es el puro rescate de la figura misma de Platón. La perspectiva nietzscheana es plenamente platónica en cuanto a su gestualidad aristocrática: se trata de crear - es decir, de generar una voluntad de verdad como voluntad de poder. Pero supone una inversión en cuanto a su producto: frente a la perfección y eternidad que suponen las Ideas -fundamentando una voluntad de verdad como impotencia de la voluntad de crearNietzsche concebirá una vitalidad activa, deveniente, una vida como voluntad de poder. Nietzsche no borrará el gesto creativo; antes bien, lo asumirá como explícito. El gesto creador y lo creado, si bien diferentes, irán en la misma línea.

\footnotetext{
7 Además de las prácticas de los sacerdotes cristianos, al referirse a las 'filosofías dogmáticas' Nietzsche asimismo pone como ejemplo a la doctrina asiática del Vedanta (NIETZSCHE, 2007a, p. 23). Tanto unos como otros combinan acciones prácticas y teóricas.

${ }^{8}$ Del mismo modo, el asceta pertenece a los síes creadores de la vida pero su producto será, finalmente, el nihilismo agobiado.
} 
Se abordará ahora la crítica heideggeriana, que se aparta tanto de la línea de lectura que pone a Platón en completa oposición a Nietzsche como de aquella que recusa al platonismo, pero rescata a Platón: Heidegger pone a ambos en continuidad metafísica.

\section{Heidegger: Platón, la vida y la voluntad de poder}

La lectura heideggeriana sobre Nietzsche -llevada a cabo en varios cursos, y compilada en el Nietzsche- ha sido asimismo objeto de múltiples comentarios. Por mencionar algunas, las críticas y revisiones a la crítica de Heidegger a Nietzsche de Vermal (2010), Constante (2001), Véliz Rodríguez y Montagud Vicó (2014) -así como algunas más clásicas, como las de Löwith (1946), Krell (1976) o Thiele (1994)- recorren los diversos cursos heideggerianos relativos al tema, haciendo hincapié en la ontologización y reducción, por parte de Heidegger, de múltiples aspectos de la perspectiva nietzscheana, el interés de presentarse -al poner a Nietzsche como el último metafísico- como el primer posmetafísico, la intención (especialmente trabajada en el texto de Rodríguez y Vicó) de desligarse de su cercanía con el nacionalsocialismo. En función de los objetivos de este trabajo, se abordará centralmente la relación trazada por Heidegger entre Nietzsche y Platón, articulando, cuando sea necesario, con otros puntos de la crítica heideggeriana.

El 'platonismo invertido' de Nietzsche es leído por Heidegger como continuidad metafísica. En efecto, '[e]n tanto este Arriba y Abajo determina la forma estructural del platonismo, él [Nietzsche] se mantiene esencialmente dentro.' (HEIDEGGER, 2000, p. 233). Frente a la aseveración nietzscheana de que '[h]emos suprimido el mundo verdadero: ¿qué mundo queda? ¿el aparente quizá?... ¡Pues no! ¡con el mundo verdadero también hemos suprimido el aparente!' (NIETZSCHE, 2007b, p. 57), Heidegger sostiene:

El mundo verdadero es el del devenir; el mundo aparente aquel que es estable y permanente. Los mundos verdadero y aparente han intercambiado lugares, rangos y formas. Pero en este intercambio e inversión la distinción entre mundo verdadero y aparente se mantiene. (2000, p. 617)

Lo que Heidegger niega es que en Nietzsche se haya producido una supresión: lo verdadero y lo aparente se mantienen, invertidos. Las ideas, como aquello permanente y estable, resultarían entonces lo aparente, mientras que la vida como voluntad de poder, aquello que deviene, lo verdadero. Ahora bien, Nietzsche es quien afirma que

[...] podría venir alguien que con una intención y un arte interpretativo antitéticos supiese sacar de la lectura de esta misma naturaleza, y en relación a los mismos fenómenos, cabalmente el triunfo tiránico, despiadado e inexorable de pretensiones de poder- un intérprete que os pusiese de tal modo ante los ojos la universalidad e incondicionalidad vigentes en toda 'voluntad de poder' [...] Suponiendo que también esto sea nada más que interpretación - ¿y no os apresuraréis vosotros a hacer esta objeción?- bien, tanto mejor.' (2007a, p. 38).

Así, Vattimo sostiene que Nietzsche propone una nueva fábula 'que se reconoce en su carácter de fábula' (2002, p. 75). ¿Por qué es la vida como voluntad de poder lo puesto como fábula por Nietzsche -por qué esa fábula y no otra? Respecto de un libro de Paul Reé, Nietzsche afirma: 
[e]n la obra antes mencionada [...] me referí a con ocasión y sin ella, a las tesis de aquél, no refutándolas -iqué me importan a mí las refutaciones!- sino, cual conviene a un espíritu positivo, poniendo, en lugar de lo inverosímil, algo más verosímil, y en lugar de un error, otro distinto. $(2000$, p. 16).

Según Heidegger, "[v]oluntad de poder, devenir, vida y ser en el más amplio sentido significan en el lenguaje de Nietzsche lo mismo" (2000, p. 394). Sin embargo, para desplegar la pregunta anterior -por qué esa fábula y no otra- se tomará un abordaje metodológico diverso al heideggeriano: vida y voluntad de poder como no equivalentes.

Como Nietzsche establece, no se trata de refutar, sino de poner otra cosa en el lugar en disputa. En vez del yo, la res cogitans, la Idea, (el Espíritu), Nietzsche pone la vida. Y en vez de una vida pensada a la manera darwiniano-spenceriana, como adaptación al medio, pone una vida con fuerzas activas, una vida como voluntad de poder. Si se trata de fábulas que se reconocen como tales, la pregunta retorna: ¿por qué esa fábula -ese error- y no otra? Respecto a la vida, Nietzsche afirma:

Por lo visto hay que alargar mucho la mano para poder atrapar esa sutilísima verdad de que el valor de la vida no puede apreciarse. No puede ser apreciado por los vivos, porque es parte y hasta objeto del litigio, y no juez; ni puede ser apreciado por un muerto, por otras razones. $(2007 \mathrm{~b}$, p. 25$)$

Frente al yo y la res cogitans -con capacidad autorreflexiva, es decir, con capacidad de ponerse completamente como objeto de evaluación ante sí mismos-, a las Ideas -con entidad de objeto externo- y al Espíritu -como síntesis de ambos aspectos-, la vida no es un algo externo al valorante, y se presenta opaca a la autorreflexión. La vida es lo único de lo cual no es posible apreciar el valor. Asimismo, Nietzsche afirma: 'El 'ser' -no tenemos para él otra representación 9 más que 'vivir'- ¿Cómo puede entonces 'ser' algo muerto?' (2008, 2 [172], p. 130). En tanto el viviente como tal es parte de la vida y no puede -según la cita previa a ésta- generar una distancia autorreflexiva de la misma, su capacidad representativa no podrá sino producirse desde la ligazón misma para con la vida; la perspectiva del viviente jamás es pura, sino parcial y contaminada -de vida.

¿Por qué entonces la fábula de la vida, antes que las otras? Porque resulta más -desde el término usado por Nietzsche- verosímil: da cuenta de que el propio punto de partida resulta opaco y parcial, y que por ende la capacidad representativa siempre estará contaminada por aquel -nunca será pura. Dicho de otro modo, centralmente da cuenta del carácter mismo de ficcionalidad: en tanto la vida nunca es captable como tal -nunca es pasible de ser puesta como objeto total- ese punto ciego da necesario curso a la generación de fábulas. Pensar la capacidad creativa y representativa en términos de la vida resulta así más 'verosímil' que hacerlo desde aquellos puntos de vista que recrean la objetividad - es decir que, desde Nietzsche, comparten la falla de aquello creado por Platón: la estabilidad y permanencia.

\footnotetext{
9 Quizá la utilización del término mediador 'representación' (Vorstellung) pueda conducir a la noción de que ese 'vivir' (erleben) resulta secundario, o derivado, respecto de ese 'ser' (Sein). Sin embargo, otro fragmento de esa época ilustra adecuadamente el sentido en que Nietzsche utiliza aquí 'representación': 'Partiendo de una representación (Vorstellung) de la vida (que no es un querer-conservarse sino un querer-crecer), he lanzado una mirada sobre los instintos fundamentales de nuestro movimiento político, espiritual y social en Europa.' (2008, 2[179], p. 131). La representación (Vorstellung) implica aquí entonces la perspectiva central, rectora, a partir de la cual Nietzsche lanza su mirada: la vida como un querer-crecer. Al estipular Nietzsche que del ser no se tiene otra representación (Vorstellung) que el vivir, está marcando que es a partir de la perspectiva del vivir que puede pensarse ese ser, o más bien, que no hay un ser por detrás de la perspectiva del vivir -y por ende, no puede pensarse el ser de algo muerto.
} 
¿Y qué sucede con la voluntad de poder? La fábula que es la vida como voluntad de poder apunta a una específica confrontación, aquella con la concepción predominante de su época: vida como adaptación al medio. Como elaboramos en el análisis del 'anti-Darwin', Nietzsche busca dar cuenta de la fabulación que implica la concepción darwiniana de vida -por ejemplo, en la trasposición de la economía malthusiana en economía de lo natural; sin embargo, nuevamente, no se trata de reemplazar una fábula por una verdad, sino 'un error por otro'. Como se estableció en el correspondiente apartado, el uso de la teleología como herramienta táctica no hace sino dar cuenta del carácter de historización propio de esa fábula que es la vida como voluntad de poder. El conflicto pasa por la valoración determinada que se sostiene tras dicha concepción de vida.

Como se había marcado, estos dos aspectos relativos a la perspectiva nietzscheana -la ficcionalidad desplegada en la vida, y la fábula específica que supone la vida como voluntad de poder- no son reconocidos como tales por Heidegger: vida, voluntad de poder, devenir, ser, son lo mismo en Nietzsche. 'Al pensamiento nietzscheano de la voluntad de poder lo denominamos su pensamiento único.' (2000, p. 389). Todo es subsumible, de hecho, en la noción de voluntad de poder como vida que tiende al acrecentamiento, al plus de poder. Con este movimiento heideggeriano, lo que se oblitera es el carácter de parcialidad y opacidad propio del punto de partida que supone la vida. De hecho, Heidegger toma el fragmento nietzscheano -'El 'ser' -no tenemos para él otra representación más que 'vivir' - ¿Cómo puede entonces 'ser' algo muerto?' $(2008,2$ [172], p. 130)- para dar cuenta que Nietzsche no sale de la representatividad en sí10, es decir, no se pregunta por sus condiciones de posibilidad ( $c f r$. HEIDEGGER, 2004, n. 110) -lo cual implicaría, en Heidegger, preguntarse por la verdad en términos de ocultamiento y desocultamiento. Sin embargo, lo obliterado por Heidegger en cuanto a la vida es justamente lo que despliega las condiciones de posibilidad de la representatividad en Nietzsche: la parcialidad y opacidad propias de la vida en tanto punto de partida vuelven necesaria la dinámica ficcional que hace de toda perspectiva una representación. La perspectiva vital no puede sino ser completada ficcionalmente desde una valoración determinada -valoración en tanto no hay objeto, por la naturaleza misma del punto de partida. Lo que dichas condiciones de posibilidad disponen es que no hay sino representatividad -no hay un ser por detrás, del cual se es representación.

Respecto a esto, Heidegger establece:

[1]a metafísica de Nietzsche no se limita únicamente a interpretar el ser a partir del ente en la orientación impuesta por la voluntad de poder, concebida como un valor, sino que llega incluso a interpretar pensar esta voluntad como principio de una nueva institución de valores. En este sentido se le revela también como aquello que hace posible la superación del nihilismo. $\mathrm{Y}$ es entonces justamente cuando el hundimiento absoluto de la metafísica en la inautenticidad del nihilismo es evidenciado por la voluntad misma de trascenderlo. De tal modo ocurre esto, que el hundimiento disimula su propia esencia, y así, bajo la forma de una reducción, no hace otra cosa que trasponer el nihilismo al plano del eficaz desencadenamiento de su de-esencia (Unwesen). (2000b, p. 301)

Interpretar el ser a partir del ente: desde la misma lógica en que concibe su crítica a la representación, Heidegger sostiene que la perspectiva nietzscheana es metafísica al continuar la historia del olvido del ser. En tanto voluntad de poder es lo mismo que vida y ser, el ser está entonces pensado desde los caracteres propios del ente que es la vida, a partir de la valoración particular que le imprime Nietzsche. Desde Heidegger, 'la transvaloración de Nietzsche es en el

${ }^{10}$ Heidegger hace la misma afirmación sobre Liebniz.

ZENGOTITA, Alonso. Nietzsche, Platón y Darwin: vida, creación y nihilismo. Griot : Revista de Filosofia, Amargosa - BA, v.20, n.2, p.244-257, junho, 2020. 
fondo el repensar en términos de valor todas las determinaciones del ente.' (2000b, p. 95). Que se piense una nueva institución de valores es concebido, desde Nietzsche, como superación del nihilismo; pero el hecho de que esa nueva institución se produzca puramente desde el dominio del ente provoca el efecto opuesto: hunde completamente a esa metafísica en el nihilismo. En este punto se conectan, reuniéndose, la crítica a la representación con la concepción metafísica. En efecto, si no hay nada sino representación dada articuladamente a una valoración determinada, se produce un olvido de sus condiciones de posibilidad en cuanto al ocultamiento y desocultamiento del ser; si el ser no es sino vida pensada también desde una cierta axiología como voluntad de poder- lo que importa es el valor del ente, y en lo explícito de esta posición no se produce una superación sino una exacerbación del ocultamiento -el ser queda completamente cubierto por algo que se presenta a sí mismo como ser, pero corrido completamente de los caracteres del ser, una determinada perspectiva subjetiva, un valor. Como afirma Heidegger, 'el valor no le deja ser al ser'. (2000b, p. 102). Representación sin pregunta por su fundamento y visión metafísica se reúnen: ambas se producen a partir de la obliteración del plano del ser.

Ahora bien, como se había establecido, no se trata de que Nietzsche no haya inquirido sobre las condiciones de posibilidad de la representación, sino que en su lectura de la vida como voluntad de poder Heidegger oblitera dichas condiciones. Dicha obliteración es lo que permite la igualación entre vida y voluntad de poder ${ }^{11}$-y ser, y devenir-, fungiendo como condición de posibilidad para equiparar en bloque a Nietzsche y Platón en cuanto metafísicos. Por el contrario, el análisis llevado a cabo, al dar a la vida y a la voluntad de poder su especificidad propia, permite distinguir entre un plano de equiparación entre Nietzsche y Platón -aquel del gesto creativo, concebido desde el carácter de ficcionalidad abierto por la condición de posibilidad que implican la parcialidad y opacidad propias de la vida, en términos de perspectiva- y un plano de divergencia -donde se piensa la estabilidad y permanencia de las Ideas, frente a una vida concebida en los términos de la voluntad de poder. Desde aquí -la fábula en tanto que fábula- la noción heideggeriana de la igualdad entre ser, vida, voluntad de poder y devenir no se sostiene, y por ende el sostenimiento de la estructura platónica de un Arriba y Abajo - de una diferencia radical entre verdad y apariencia- tampoco.

\section{Conclusión: nihilismo, creatividad y disrupción}

En el presente artículo se ha comenzado por Darwin por ser lo menos explorado, porque la crítica a Platón es más explícita y extendida en Nietzsche. Si la lectura más general, canónica, dirá que Nietzsche tiene como principal figura de oposición al platonismo, y sólo como consecuencia, en un segundo momento, al darwinismo, se establecerá que esto es verdadero sólo parcialmente. No son sino dos elementos de la misma crítica, aquella de la civilización occidental $^{12}$, históricamente desplegada: justamente porque a Platón le sigue Darwin -dándose, en medio, ni más ni menos que el cristianismo- es que la modificación de la posición nietzscheana respecto al adversario se produce: de acordar parcialmente con Platón -es decir, de encontrar un parcial plano de superposición- a desacordar totalmente con Darwin. Desde la lectura aquí desarrollada, el 'platonismo invertido' se da en la coincidencia de lo platónico y lo nietzscheano

11 Es lo que asimismo permite poner a la vida como un principio único que no busca sino lo que valora como puro acrecentamiento, de modo que Heidegger puede afirmar que la filosofía nietzscheana funciona "poniendo en seguro de antemano la dominación técnica moderna' (2000b, p. 302). Nietzsche como la vanagloria de la tecnociencia, el Übermensch como el técnico supremo.

12 Civilización y no cultura; en efecto, Nietzsche diferencia Zivilisation de Kultur, donde la primera propende a una vida descendente, mientras la segunda implica una tendencia al acrecentamiento vital. "no confundir los medios disolventes de la civilización, que llevan necesariamente a la décadence, con la cultura.' (2008, 15[67], p. 652). 
en el gesto aristocrático, y en la divergencia -radical- de aquello creado a partir del gesto -las Ideas, la vida como voluntad de poder. Respecto al darwinismo, la divergencia resulta total: no existe allí gesto aristocrático -en eso consiste la 'teleología superflua' darwiniano-spenceriana- y aquello postulado, la vida como adaptación al medio, no es sino continuación de los valores cristianos -continuación, a su vez, del platonismo. Por ello la postura nietzscheana es la de 'antiDarwin'. Desde este punto de vista, la perspectiva es la opuesta respecto a la canónica: la principal oposición no es con Platón, sino con Darwin ${ }^{13}$. Este punto de vista puede caracterizárselo como de distancia: la perspectiva nietzscheana, al no tener coincidencia ninguna con la darwiniana, se halla a una mayor distancia que la que tiene con la platónica ${ }^{14}$. Ahora bien, como se había afirmado, sólo hay una parcial disconformidad con la lectura canónica: algo hay de verdadero en la mirada que pone a Platón como principal opositor a Nietzsche, respecto a Darwin. En efecto, 'el peor, el más duradero y peligroso de todos los errores ha sido hasta ahora un error de dogmáticos, a saber, la invención por Platón del espíritu puro y del bien en sí.' (NIETZSCHE, 2007a, p. 22). Si en términos de distancia la perspectiva canónica resulta errónea, puede caracterizarse como correcta en términos de intensidad. La platónica es la más peligrosa, peor, más duradera perspectiva. ¿Por qué es más peligrosa que la darwiniana, por qué, en términos intensivos, sí puede decirse que el platonismo aparece como principal antagonista? Justamente por la mayor cercanía -la menor distancia- que presenta respecto a la línea nietzscheana: allí hay asimismo un gesto aristocrático, creador, que falta en el darwinismo. El platonismo -así como la mirada nietzscheana- posee la capacidad activa de la cual carece el darwinismo, lo cual lo vuelve vitalmente más peligroso, potencialmente un mayor enemigo. En Darwin la creatividad ya no está: su teleología es 'superflua' justamente porque no hace sino poner lo mismo creado por el platonismo, sólo que disfrazándolo, dándole una cubierta cientificista, para hacerlo pasar por 'objetivo'; en esa falta de creatividad está el cansancio nihilista de la vida.

Según Heidegger, el nihilismo está en Nietzsche, y exacerbado: en el propio intento de superarlo, al realizarse desde el esquema metafísico -el Arriba y Abajo- no se logra sino profundizarlo. Nietzsche queda atrapado en una inmanencia -al no preguntarse por las condiciones de posibilidad de la representación, quedando remitido al puro plano del ente- de la cual elige a un ente -la vida- como punto de partida de la valoración de lo que hay; la apariencia no se supera, sino que es identificada con el mundo de las Ideas platónico -desplegado asimismo en la conceptualidad lingüística- y la verdad será la vida como voluntad de poder. El nihilismo ha sido profundizado en tanto que, remitido solamente al plano del ente, queda totalmente coartado el plano del ser. Nietzsche, el último -y más extremo- metafísico. Ahora bien, desde el análisis aquí desplegado, no se trata de que Nietzsche no haya considerado las condiciones de posibilidad de la representación, sino que éstas suponen una negación de la posibilidad de concebir a la esencia de la verdad en términos de ocultamiento y desocultamiento. La oclusión de dichas condiciones de posibilidad resulta la base del -podríamos decir- recurso táctico heideggeriano que equipara vida y voluntad de poder en Nietzsche, permitiendo entonces disponer a éste como continuidad estructural platónica. Ahora bien, como Nietzsche establece,

\footnotetext{
13 Aquí puede objetarse: hay una continua ambigüedad entre Platón y platonismo, Darwin y darwinismo... ¿Se los está utilizando de modo equivalente? Para el análisis aquí desplegado, lo determinante es la manera en que se opera la relación de conjuntos: Nietzsche encuentra intersección respecto al gesto aristocrático y disyunción respecto a lo creado en relación al platonismo, y disyunción respecto a ambas variables en relación al darwinismo. En vistas de dicho análisis estructural -es decir, un análisis que no toma en cuenta lo particular de las figuras como tales- reemplazar en el enunciado precedente 'platonismo' por 'Platón' y/o 'darwinismo' por 'Darwin' no modifica el valor de verdad del mismo.

14 Esto es equiparable con la noción de 'mirada aristocrática' frente a la 'corta visión sensualista' trabajadas en el primer apartado.
} 
[1] a creencia en el mundo que debería ser, es, existe realmente, es una creencia de improductivos que no quieren crear un mundo tal como debe ser. Lo ponen como existente, buscan los medios y caminos para llegar a él. 'Voluntad de verdad' como impotencia de la voluntad de crear. (2008, 9[60], p. 250)

Mientras que Nietzsche piensa al nihilismo como falta de querer (crear), Heidegger lo pensará como falta de ser; pensarlo en términos de ser pone a Heidegger, desde la perspectiva nietzscheana, como retorno al platonismo ${ }^{15}$. Desde Nietzsche, que se postule el plano del ser diferenciado de aquel del ente supone una voluntad de verdad-una que oblitera las condiciones de opacidad y parcialidad desde las que se produce la representación. En tanto retorno al platonismo, la perspectiva heideggeriana carece del gesto aristocrático: desde el análisis aquí desplegado presenta entonces un carácter darwiniano, poniéndola en total oposición y lejanía a la nietzscheana.

La postura de Nietzsche con Darwin, por un lado, y con Platón, por el otro, no pueden comprenderse cabalmente si no es articulándolas, en tanto son ambas parte de la misma historia -aquella de la civilización occidental, tendiente a la vida descendente. Esta tendencia descendente da cuenta históricamente de su carácter al mostrar cómo la creatividad vital fue apagándose: desde Platón, pasando por el cristianismo, hasta Darwin, el gesto aristocrático se ha perdido; no hay sino continuos recubrimientos de la misma idea -de los mismos valores. Si para Heidegger la historia de occidente es aquella del olvido del ser, con su exponente último y más exacerbado dado en Nietzsche, desde Nietzsche podríamos decir que se trata del olvido de la ficcionalidad misma de la verdad, y con este, del gesto aristocrático asociado; Heidegger no sería sino un gastado retorno al platonismo - al ser, a la verdad- una nueva máscara del nihilismo.

Heidegger caracteriza, al equiparar vida y voluntad de poder, a Nietzsche como aquel que pone 'en seguro de antemano la dominación técnica moderna' (2000b, p. 302). A través del recorrido analítico de las perspectivas nietzscheanas sobre Darwin y Platón se abre una diferenciación de planos que permite visualizar al gesto aristocrático nietzscheano no como simple dominio, sino centralmente como creador, al desplegarlo no desde una vida con pura ansia de poder, sino desde la perspectiva de la parcialidad y opacidad de lo propiamente vital; esto permite divergir de la calificación heideggeriana, y hacer de la nietzscheana una línea con potencialidad disruptiva para con los valores que sustentan la dominación de la técnica moderna.

\footnotetext{
15 Como sostiene Constante, "si para Heidegger el pensador de Basilea permanece siendo metafísico, desde el punto de vista de Nietzsche, el metafísico es Heidegger" (2001, p. 111).
} 


\section{Referencias}

BACARLETT PEREZ, M. L. Friedrich Nietzsche: la vida, el cuerpo la enfermedad. DF: Univ. Autónoma de Méjico. 2006.

BROBJER, T. Nietzsche's Wrestling with Plato and Platonism. En Bishop, Boydell y Brewer (eds.), Nietzsche and Antiquity: His Reaction and Response to the Classical Tradition (241-259). Columbia: Cadmen House. 2004.

CANO, V. Is evolution blind? On Nietzsche's reception of Darwin. En Nietzsche and the Becoming of Life (51-67), NY: Fordham Univ. Press. 2015.

CONSTANTE, A. A propósito del Nietzsche de Heidegger. Signos filosóficos, UAM, 6, 85-112. 2001.

FORNARI, M. C. Nietzsche y el darwinismo. Journal of Nietzsche Studies, Penn State Univ. Press, 23, 89-119. 2002.

HEIDEGGER, M. Nietzsche I (trad. Juan Luis Vermal). Barcelona: Destino. 2000.

HEIDEGGER, M. Nietzsche II (trad. Jan Luis Vermal). Barcelona: Destino. 2000b.

HEIDEGGER, M. Gesamtausgabe 87 -Nietzsche: Seminare 1937 und 1944. Peter von Ruckteschell (ed). Barcelona: Herder. 2004.

KRELL, D. F. Art and Truth in Raging Discord: Heidegger and Nietzsche on the Will to Power. Martin Heidegger and Literature. Duke Univ. Press, 4 (2), 378-392. 1976.

LAMPERT, L. Nietzsche's Wrestling with Plato and Platonism. En Bishop, Boydell y Brewer (eds.), Nietzsche and Antiquity: His Reaction and Response to the Classical Tradition (205-219). Columbia: Cadmen House. 2004.

MANSILLA, H. F. C. Aspectos socio-políticos del relativismo desde Friedrich Nietzsche hasta la escuela de Frankfurt. Daimon, 45, 50-56, 2007.

MÜLLER, E. Diálogo crítico de Nietzsche con Platón. Estudios Nietzsche, 11, 67-81. 2011.

NIETZSCHE, F. Más allá del bien y del mal. Madrid: Alianza. 2007a.

NIETZSCHE, F. Fragmentos póstumos. Madrid: Tecnos. 2008.

NIETZSCHE, F. Genealogía de la moral. Madrid. Alianza. 2000.

NIETZSCHE, F. El crepúsculo de los ídolos. Madrid. Alianza. 2007b.

NORRIS, M. Darwin, Nietzsche, Kafka and the Problem of Mimesis. MLN, Johns Hopkins Univ, Press, 95 (5), pp. 1232-1253. 1990.

RICHARDSON, J. Nietzsche contra Darwin. Philosophy and Phenomenological Research, 65 (3), 537575. 2002.

SÁNCHEZ TABORDA, C. A. Crítica y moral. Katharsis, 14, 49-67. 2012.

SEIGFRIED, H. Autonomy and Quantum Physics: Nietzsche, Heidegger, and Heisenberg. Philosophy of Science, 57 (4), 619-630. 1990.

SENA, M. Nietzsche's New Grounding of the Metaphisycal: Sensuousness and the Subversion of Plato and Platonism. Research in Phenomenology, 34, 139-159. 2004.

VATTIMO, G. Diálogo con Nietzsche. Buenos Aires: Paidós. 2002.

VÉLIZ RODRÍGUEZ, S. B., y MONTAGUD MICÓ, A. Nietzsche desenmascara a Heidegger. El genio maligno, 15, 21-54. 2014.

VERMAL, J. L. Acerca de la inversión del platonismo en Nietzsche y Heidegger. Estudios Nietzsche, 10,97-111. 2010.

WIEHL, R. Nietzsches Anti-Platonismus. Courtine, J.-F., En Brague, R. (ed.) Herméneutique et ontologie: Melanges en hommage a Pierre Aubenque (152-174). París: Rewiew. 1990.

Autor(a) para correspondência:

Alonso Zengotit, Av. Santa Fe 3282 1B, CP 1425, CABA, Argentina. alonsozengotita@gmail.com 